\title{
X AND Y CHROMATIN SURVEY AMONG 1,581 JAPANESE JUVENILE DELINQUENTS
}

\author{
Shinichiro NANKo, ${ }^{*, * *}$ Shunichi SAITo,* and Masaru MAKINo* \\ *Yokohama Juvenile Detention and Classification Home, Yokohama \\ **Institute of Brain Resarch, University of Tokyo School of Medicine, Tokyo
}

\begin{abstract}
Summary Consecutive $\mathrm{X}$ and $\mathrm{Y}$ chromatin survey among 1,581 Japanese juvenile delinquents had been undertaken for three years. Among 1,371 males, five $47, \mathrm{XYY}$ males and four $47, \mathrm{XXY}$ males were found $(0.36 \%$ and $0.29 \%$ respectively), while no numerical abnormalities of $X$ chromatin were found in 210 females. Frequency of 47,XYY males in the present study is significantly higher than that of newborns. With respect to sample size, for which the frequencies of $47, \mathrm{XYY}$ and $47, \mathrm{XXY}$ males have been estimated, a possible bias in the studies reported previously was suggested.
\end{abstract}

\section{INTRODUCTION}

Since the original study of Jacobs et al. (1965), many authors have reported an unusually high frequency of $47, \mathrm{XYY}$ males among criminals. The present study was undertaken to estimate the frequency of abnormal sex chromosome individuals among Japanese juvenile delinquents. The present finding in male delinquents will be discussed in connection with the results of previous studies.

\section{MATERIALS AND METHODS}

$\mathrm{X}$ and $\mathrm{Y}$ chromatin survey was performed on consecutive cases for a period from February 12, 1974 to February 11, 1977 at Yokohama Juvenile Detention and Classification Home. With the consent of the subject, new admissions were screened on weekly or biweekly basis. X chromatin screening by cresyl-violet staining of buccal smear was performed in both sexes, and $\mathrm{Y}$ chromatin by quinacrine mustard staining of blood smear only in males. If numerical abnormalities of chromatin were indicated, peripheral lymphocyte culture and karyotyping were performed.

During the period of three years, the total numbers of admissions excluding non-Japanese were 1,670 males and 251 females, among whom 1,371 males and 210 females were examined. 


\section{RESULTS}

Double $Y$ chromatin bodies were found in five males and the karyotype was confirmed to be $47, \mathrm{XYY}$ in all cases by standard Giemsa and quinacrine mustard stainings. Four males with positive $\mathrm{X}$ chromatin had a $47, \mathrm{XXY}$ constitution. None of the females showed numerical $X$ chromatin abnormality.

\section{DISCUSSION}

Among 1,371 males, five 47,XYY males and four 47,XXY males were found, and the frequencies are $0.36 \%$ and $0.29 \%$, respectively. Table 1 shows the results of previous surveys on the frequencies of $47, \mathrm{XYY}$ and $47, \mathrm{XXY}$ males among juvenile

Table 1. Surveys of 47,XYY and 47,XXY males among juvenile delinquents.

\begin{tabular}{|c|c|c|c|c|c|}
\hline & Authors & Country & Examined & $\mathrm{XYY}$ & $\mathrm{XXY}$ \\
\hline 1 & Wegmann and Smith (1963) & U.S.A. & 505 & - & 0 \\
\hline 2 & Inouye and Kurihara (1969) & Japan & 2,361 & - & 5 \\
\hline 3 & Marinello et al. (1969) & U.S.A. & 15 & 0 & - \\
\hline 4 & do. & & 42 & 1 & - \\
\hline 5 & Kahn et al. (1969) & England & 387 & 2 & 0 \\
\hline 6 & do. & & 200 & 0 & 2 \\
\hline 7 & Ferrier et al. (1969) & U.S.A. & 103 & 0 & 2 \\
\hline 8 & Matsaniotis et al. (1970) & Greece & 59 & 1 & 1 \\
\hline 9 & do. & & 80 & 1 & 0 \\
\hline 10 & Hook and Kim (1971) & U.S.A. & 337 & 4 & 2 \\
\hline 11 & Hübner (1971) & Poland & 30 & 0 & 0 \\
\hline 12 & Asaka et al. (1971) & Japan & 113 & 1 & 2 \\
\hline 13 & Jacobs et al. (1971) & Scotland & 607 & 1 & 2 \\
\hline 14 & do. & & 1,119 & 4 & 2 \\
\hline 15 & Nielsen and Henriksen (1972) & Denmark & 151 & 3 & 2 \\
\hline 16 & Dodson et al. (1972) & U.S.A. & 475 & 0 & 0 \\
\hline 17 & Forsius et al. (1972) & Finland & 145 & 1 & 0 \\
\hline 18 & Mekanandha and Banpotkasem (1972) & Thailand & 100 & 1 & 1 \\
\hline 19 & Murken (1973) & Germany & 110 & 1 & 1 \\
\hline 20 & do. & & 147 & 1 & 2 \\
\hline 21 & Kovács et al. (1973) & Hungary & 173 & 1 & - \\
\hline 22 & Borgaonkar (after Hook 1973) & U.S.A. & 1,112 & 2 & 0 \\
\hline 23 & de Toni (after Hook 1973) & Italy & 145 & 2 & - \\
\hline & & & & $\begin{array}{l}27 / 5,650 \\
(0.48 \%)\end{array}$ & $\begin{array}{l}24 / 8,141 \\
\left(0.29^{\circ} \%\right)\end{array}$ \\
\hline & Present study & & 1,371 & $\begin{array}{c}5 \\
\left(0.36^{\circ} \%\right)\end{array}$ & $\begin{array}{c}4 \\
\left(0.29^{\circ} \%\right)\end{array}$ \\
\hline
\end{tabular}

-: This indicates that the survey was not performed. 
Table 2. Frequencies of $47, \mathrm{XYY}$ and $47, \mathrm{XXY}$ males among newborn males.

\begin{tabular}{lllrlrll}
\hline Authors & & Country & XYY & \multicolumn{3}{c}{ XXY } & \\
\hline Sergovich et al. & $(1969)$ & Canada & $4 / 1,066$ & $(0.38 \%)$ & $1 / 1,066$ & $(0.09 \%)$ \\
Lubs and Ruddle & $(1970)$ & U.S.A. & $3 / 2,184$ & $(0.14 \%)$ & $4 / 2,184$ & $(0.18 \%)$ \\
Bochkov et al. & $(1974)$ & U.S.S.R. & $0 / 1,303$ & $(0 \%)$ & $1 / 1,303$ & $(0.08 \%)$ \\
Jacobs et al. & $(1974)$ & Scotland & $10 / 7,849$ & $(0.13 \%)$ & $9 / 7,849$ & $(0.11 \%)$ \\
Bell and Corey & $(1974)$ & Canada & $5 / 5,395$ & $(0.09 \%)$ & $40 / 37,233$ & $(0.11 \%)$ \\
Nielsen and Sillesen & $(1975)$ & Denmark & $3 / 5,761$ & $(0.05 \%)$ & $6 / 5,761$ & $(0.10 \%)$ \\
Hamerton et al. & $(1975)$ & Canada & $4 / 7,176$ & $(0.06 \%)$ & $6 / 7,176$ & $(0.08 \%)$ \\
Goad et al. & $(1976)$ & U.S.A. & $4 / 8,011$ & $(0.05 \%)$ & $20 / 20,666$ & $(0.10 \%)$ \\
lijima and Higurashi & $(1976)$ & Japan & $3 / 2,645$ & $(0.11 \%)$ & - & \\
Walzer and Gerald & $(1977)$ & U.S.A. & $11 / 13,751$ & $(0.08 \%)$ & $9 / 13,751$ & $(0.07 \%)$ \\
\hline Total & & & $47 / 55,141$ & $(0.09 \%)$ & $96 / 96,989$ & $(0.10 \%)$ \\
\hline
\end{tabular}

Table 3. Previously reported frequencies of $47, \mathrm{XYY}$ and $47, \mathrm{XXY}$ males among juvenile delinquents according to population size.

\begin{tabular}{crrrrr}
$\begin{array}{c}\text { Population } \\
\text { size }\end{array}$ & \multicolumn{2}{c}{$\begin{array}{c}\text { Pooled frequency } \\
\text { of } 47, \mathrm{XYY} \text { males }\end{array}$} & \multicolumn{2}{c}{$\begin{array}{c}\text { Pooled frequency } \\
\text { of } 47, \mathrm{XXY} \text { males }\end{array}$} & $\begin{array}{c}\text { No. of report } \\
\text { in Table 1. }\end{array}$ \\
\hline$\leqq 100$ & $4 / 326$ & $(1.23 \%)$ & $2 / 269$ & $(0.74 \%)$ & 3.4 .8 .9 .11 .18 \\
$101-200$ & $10 / 1,287$ & $(0.78 \%)$ & $11 / 969$ & $(1.14 \%)$ & 6.7 .12 .15 .17 .19 .20 .21 .23 \\
$201-500$ & $6 / 1,199$ & $(0.50 \%)$ & $2 / 1,199$ & $(0.17 \%)$ & 5.10 .16 \\
$>501$ & $7 / 2,838$ & $(0.24 \%)$ & $9 / 5,704$ & $(0.15 \%)$ & 1.2 .13 .14 .22 \\
\hline
\end{tabular}

delinquents. Corresponding figures among newborns are in Table 2. Present results do not differ significantly from pooled frequencies of previous studies on juvenile delinquents. The present figure on 47,XYY males differs significantly from that of $47, X Y Y$ males among newborns $\left(\chi^{2}=11.9\right.$, d.f. $\left.=1, p<0.01\right)$. Although no significant difference in the frequency of $47, \mathrm{XXY}$ males is seen between the present and newborn surveys, the difference is close to the significant level.

A tendency is noted in Table 1 that as the sample size increases, the frequency of $47, \mathrm{XYY}$ males decreases. If the previous studies in this table are divided into four groups with respect to a sample size, the pooled frequency decreases from $1.23 \%$ in the first group with a sample size fewer than 100 to $0.24 \%$ in the last group with a sample size of more than 500 , as seen in Table 3 .

This result suggests the possibility that, if the sample size is small, negative data may have been discarded or may not have been reported. Therefore, caution should be exercised in findings with a sample size of less than 100 or 200. If we take the results of the studies with more than 200 subjects, the frequency of 47,XYY males among juvenile delinquents is estimated approximately $0.35 \%$, which closely agrees with the present figure. In case of $47, \mathrm{XXY}$ males, the association of the frequency with sample size is less clear than that in $47, \mathrm{XYY}$ males. However the pooled frequencies of the studies on more than 200 subjects $(0.16 \%)$ is evidently lower than the rest which examined fewer than 200 subjects $(1.05 \%)$. 
From this point of view, we may conclude that the frequency of $47, \mathrm{XYY}$ males among juvenile delinquents as well as among criminals or mental defectives may have been overestimated in the previous studies. However, the association of $47, X Y Y$ males with criminality cannot be ruled out, because the frequency of such individuals among juvenile delinquents are higher than that of newborn by all means.

\section{REFERENCES}

Asaka, A., Takemura, S., Inouye, E., Kayaba, T., Kajimura, Y., Miyazawa, S., Aoki, N., and Sugimoto, K. 1971. XXY and XYY individuals among Japanese juvenile delinquents. Acta Crim. Jpn. 37: 297-298.

Bell, A.G. and Corey, P.N. 1974. A sex chromatin and $\mathrm{Y}$ body survey of Toronto newborns. Can. J. Genet. Cytol. 16: 239-250.

Bochkov, N.P., Kuleshov, N.P., Chebotarev, A.N., Alekhin, V.I., and Midian, S.A. 1974. Population cytogenetic investigation of newborns in Moscow. Humangenetik 22: 139-152.

Dodson, W.E., Al-Aish, M.S., and Alexander, D.F. 1972. Cytogenetic survey of XYY males in two juvenile court populations. -with a case report- J. Med. Genet. 9: 287-288.

Ferrier, P.E., Ferrier, S.A., and Nielson, J. 1969. Chromosome study in a group of maladjusted boys with antisocial behaviour. Ann. Génét. 12: 247-249.

Forsius, H., Kaski, U., Schröder, J., and de la Chapelle, A. 1972. Is there a common psychopathology of XYY boys? A clinical report on three cases of XYY and one XY/XYY. Acta Paedopsychiatr. 39: 28-41.

Goad, W.B., Robinson, A., and Puck, T.T. 1967. Incidence of aneuploidy in a human population. Am. J. Hum. Genet. 28: 62-68.

Hamerton, J.L., Canning, N., Ray, M., and Smith, S. 1975. A cytogenetic survey of 14069 newborn infants. Clin. Genet. 8: 223-243.

Hook, E.B., 1973. Behavioral implications of the human XYY genotype. Science 179: 1-14.

Hook, E.B. and Kim, D.S. 1971. Prevalence of XYY and XXY karyotypes in 337 nonretarded young offenders. New. Engl. J. Med. 283 : 410-411.

Hübner, H. 1971. The $Y$ chromosome in selected groups of men of the polish population. Bull. Acad. Pol. Sci. 19: 467-472.

Iijima, K. and Higurashi, M. 1976. Incidence of XYY in consecutive newborn males in Japan. Jap. J. Hum. Genet. 21 : 199-203 (in Japanese w. English abstract).

Inouye, W. and Kurihara, T. 1969. Chromosome anomalies among criminals. Clinic All-round 18: 127-134 (in Japanese).

Jacobs, P.A., Brunton, M., Melville, M.M., Brittain, R.P., and McClemont, W.F. 1965. Aggressive behaviour, mental sub-normality and the XYY male. Nature 208: 1351-1352.

Jacobs, P.A., Price, W.H., Richmond, S., and Ratcliff, R.A.W. 1971. Chromosome surveys in penal institutions and approved schools. J. Med. Genet. 8: 49-53.

Jacobs, P.A., Melville, M., Ratcliffe, S., Keay, A.J., and Syme, J. 1974. A cytogenetic survey of 11680 newborn infants. Ann. Hum. Genet. 37: 359-376.

Kahn, J., Carter, W.I., Dernley, N., and Slater, E.T.O. 1969. Chromosome studies in remand home and prison populations. In Criminological Implications of Chromosome Abnormalities (West, D.J. ed.) Cambridge.

Kovács, M., Sellyei, M., Szabo, A., and Vass, L. 1973. Occurrence of XYY individuals among juvenile delinquents in Hungary. Humangenetik 18: 85-87.

Lubs, H.A. and Ruddle, F.H. 1970. Chromosomal abnormalities in the human populationestimation of rates based on New Haven newborn study. Science 169: 495-497. 
Marinello, M.J., Berkson, R.A., Edwards, J.A., and Bannerman, R.M. 1969. A study of the XYY syndrome in tall men and juvenile delinquents. J.A.M.A. 208: 321-325.

Matsaniotis, N., Tsenghi, C., Metaxotou-Stavridaki, C., Economou-Mavrou, C., and Bilalis, P. 1970. The XYY syndrome in young Greek detainees. Helv. Paediatr. Acta 3: 253-257.

Mekanandha, V. and Banpotkasem, S. 1972. Cytogenetic study in severe juvenile delinquents. J. Med. Assoc. Thailand 55: 32-35.

Murken, J.D. 1973. The XYY syndrome and Klinefelter's syndrome: Investigations into epidemiology, clinical picture, psychology behavior and genetics. In Topics in Human Genetics Vol. II, Becker, P.E. et al. eds. Georg Thieme Pub. (Stuttgart).

Nielsen, J. and Henriksen, F. 1972. Incidence of chromosome aberrations among males in a Danish youth prison. Acta. Psychiatr. Scand. 48: 87-102.

Nielsen, J. and Sillesen, I. 1975. Incidence of chromosome aberrations among 11148 newborn children. Humangenetik 30: 1-12.

Sergovich, F., Valentine, G.H., Chen, A.T.L., and Kinch, R.A.H. 1969. Chromosome aberrations in 2159 consecutive newborn babies. New. Engl. J. Med. 280: 851-855.

Walzer, S. and Gerald, P.S. 1977. A chromosome survey of 13751 male newborns. In Population Cytogenetics--Studies in Humans-, Hook, E.R. and Porter, I.H., eds. Academic Press New York.

Wegmann, T.G. and Smith, D.W. 1963. Incidence of Klinefelter's syndrome among juvenile delinquents and felons. Lancet i: 274. 